\title{
Infra-Red Study of Surface Carbonation on Polycrystalline Magnesium Hydroxide
}

\author{
Heekyoung Kwon and Dong Gon Park \\ Department of Chemistry, Sookmyng Women 's tinversity, Seoul 140-742, Korea. E-mail: dgparkasmackr \\ Received July 27, 2009. Accepted September 9, 2009
}

\begin{abstract}
Carbonation of $\mathrm{Mg}(\mathrm{OH})_{2}$ at $300^{\circ} \mathrm{C}$ was studied by Infrared spectroscopy. Delyydroxylation and carbonation reactions were carried out in consecutive manner via 2 -step procedure. Unidentate carbonates were produced only on defective surface of $\mathrm{MgO}$ in situ generated by dehydroxylation of $\mathrm{Mg}(\mathrm{OH})$ ? under dynamic vacuum. Bicarbonates and bidentate carbonates were not observed. Generation of unidentate carbonates was accompanied by decrease of l-coordinated hydroxides and concomitant increase of muti-coordinated hydroxides on the surface. Postulated reaction mechanism for the carbonation of $\mathrm{Mg}(\mathrm{OH})$, at $300^{\circ} \mathrm{C}$ was proposed
\end{abstract}

Key Words: Carbonation, Dehydroxỵlation. Carbonates. Hydroxides

\section{Introduction}

Much effort is being made to devise effective ways to remove atmospheric $\mathrm{CO}_{\curvearrowright}$. and to store it for extended time. ${ }^{1}$ Several approaches for the $\mathrm{CO}_{2}$-sequestration include transformation of $\mathrm{CO}_{2}$ into carbonate minerals. ${ }^{2}$ The most viable candidates for the carbonate mineralization are oxides or hydroxides of $\mathrm{Mg}$ or $\mathrm{Ca}$. They generate stable carbonates which are insoluble in water. A major obstacle in applying them for $\mathrm{CO}_{2-}$ sequestration is that the rate of carbonation is very low. Challenge is to find a practical way to enhance the carbonation process. For the purpose, it is required to expand understanding on the carbonation process of these materials.

Studies on $\mathrm{Mg}(\mathrm{OH})_{2}$ show that the carbonation process is quite complex. that exact mechanism cannot easily be clarified. ${ }^{3,4}$ Carbonation was carried out at the temperature higher than $300^{\circ} \mathrm{C}$. where reasonable conversion to $\mathrm{MgCO}_{3}$ could be reached. Apparently: many different reactions were concurrently involved with the generation of $\mathrm{MgCO}_{3}$ at the temperature range. Not only carbonation. but dehydroxylation of $\mathrm{Mg}$ $(\mathrm{OH})_{2}$ into $\mathrm{MgO}$ proceeded simultaneously. As reaction temperature was raised above $400^{\circ} \mathrm{C}$. decarbonation also started to occur. competing with the simultaneous delydroxylation and carbonation. Generation of $\mathrm{MgCO}_{3}$ layer also retarded further carbonation by pacifying surface of the solid sample. Further complicating the studies on the kinetics and mechanisms. delydroxylation accompanied morphological reconstruction as well as in situ generation of $\mathrm{MgO}$ phase. ${ }^{5.7}$ Therefore. fundamental understanding of the oxide surfaces is also necessary to fully describe carbonation of $\mathrm{Mg}(\mathrm{OH})_{2}$. Surfaces of metal oxides play an important role in various solid-gas reactions occurring in nature or in industrial processes. such as catalysis. corrosion and many geological processes. ${ }^{8}$

In this report conversion of $\mathrm{Mg}(\mathrm{OH})_{2}$ into $\mathrm{MgCO}_{3}$ was carried out via 2-step reactions at low temperature of $300^{\circ} \mathrm{C}$. and reactions occurring on the solid surface were investigated by Fourier transformed infrared (FTIR) spectroscopy:

\section{Experimentals}

$\mathrm{Mg}(\mathrm{OH})_{2}$ was prepared by hydration of commercial $\mathrm{MgO}$ (99\%. 325 mesh) purchased from Sigma-Aldrich. In I-L round bottom flask equipped with a water condenser. $20 \mathrm{~g}$ of $\mathrm{MgO}$ was dispersed in $500 \mathrm{~mL}$ distilled water. The mixture was refluxed for $24 \mathrm{~h}$. The white paste obtained by filtration was dried in oven at $120^{\circ} \mathrm{C}$ overnight. Fine white powder of $\mathrm{Mg}$ $(\mathrm{OH})_{2}$ was obtained after brief grinding by agate mortar and pestle.

Pre-treatment and carbonation reaction were carried out in $100 \mathrm{~mL}$ Schlenk reaction vessel (SRV) attached to double manifold inert-atmosphere system. The manifold for inert gas was modified so that $\mathrm{Ar} . \mathrm{CO}_{2}$. or dynamic vacuum could be switched at will. without any internuption during heat treatment. In the $100 \mathrm{~mL}$ SRV. $3.0 \mathrm{~g}$ of $\mathrm{Mg}(\mathrm{OH})_{2}$ powder was loaded. then was heated at $300^{\circ} \mathrm{C}$ (or $500{ }^{\circ} \mathrm{C}$ ) by using the home-made heater. The flow rate of the gas was $33 \mathrm{~mL} / \mathrm{min}$.

FTIR spectrum was taken by JASCO 670 FTIR spectrometer from powder sample pelletized with $\mathrm{KBr}$. Powder sample in SRV was taken out and made into pellet under Ar atmosphere in VAC glove box. The $\mathrm{KBr}$ pellet was made by using small bolt-type pellet presser purchased from SigmaAldrich. and kept as standing in the bolt under dry Ar all the time, thereby eliminating contact with atmospheric $\mathrm{CO}_{2}$ or moisture. Powder $\mathrm{X}$-ray diffraction pattern was taken with AXS-D8 ADVANCE diffractometer from Bruker. By using modified sample holder covered by Mylar film. contact with atmospheric $\mathrm{CO}_{2}$ or moisture was eliminated. BET surface area was measured by GEMINI V from Micromeritics.

\section{Results and Discussion}

$\mathrm{Mg}$ and $\mathrm{Ca}$ are abundant elements on earth. and their oxides and hydroxides are relatively cheap and readily available. The capture of $\mathrm{CO}_{2}$ by these oxides or hỵdroxides may occur by one of following reactions. 


$$
\begin{aligned}
& \mathrm{MgO}(\mathrm{s})+\mathrm{CO}_{2}(\mathrm{~g}) \rightarrow \mathrm{MgCO}_{3}(\mathrm{~s}) \\
& \mathrm{CaO}(\mathrm{s})+\mathrm{CO}_{2}(\mathrm{~g}) \rightarrow \mathrm{CaCO}_{3}(\mathrm{~s}) \\
& \mathrm{Mg}(\mathrm{OH})_{2}(\mathrm{~s})+\mathrm{CO}_{2}(\mathrm{~g}) \rightarrow \mathrm{MgCO}_{3}(\mathrm{~s})+\mathrm{H}_{2} \mathrm{O}(\mathrm{g}) \\
& \mathrm{Ca}(\mathrm{OH})_{2}(\mathrm{~s})+\mathrm{CO}_{2}(\mathrm{~g}) \rightarrow \mathrm{CaCO}_{3}(\mathrm{~s})+\mathrm{H}_{2} \mathrm{O}(\mathrm{g})
\end{aligned}
$$

Carbonation in practice is carried out in dynamic flow of reactant gases, which is non-equilibrium condition. In such dy namic sy stem. the partial pressure of gas product never reaches standard state of 1 atm. Therefore. thermody namic parameters in the Table 1 do not exactly reflect the real conditions. Still. thermodynamic parameters tabulated for the standard state in equilibrium may provide instnictive insight on the consequences from raising temperature in the real situation.

A brief calculation of a few basic themodynamic parameters (provided in Table 1) suggests that Ca minerals may be better candidates for locking off $\mathrm{CO}_{2}$ into carbonate minerals than $\mathrm{Mg}$. Carbonation of $\mathrm{Ca}$ minerals is strongly inclined toward forward reaction (large negative values of $\Delta \mathrm{G}_{\text {reacton }}^{\circ}$ ). Historical human experience already demonstrated this aspect. by Romans heavily using slaked lime $\left[\mathrm{Ca}(\mathrm{OH})_{2}\right]$ as mortar in construction. Buildings and aqueducts whose bricks were glued together with $\mathrm{CaCO}_{3}$ in situ generated from the $\mathrm{Ca}(\mathrm{OH})_{2}$ used. are still standing after several hundred years. But, for some technical purposes. one might need to reverse the carbonation reaction at will. to release $\mathrm{CO}_{2}$ at some point. thereby refreshing sequestrating reagents for recycle. For such specific purpose $\mathrm{Mg}$ minerals could be better candidates than $\mathrm{Ca}$.

In any case. rate for carbonation at ambient temperature is too slow to be practical. From previous studies by others it was demonstrated that the temperature had to be raised, in order to accomplish carbonation in practical rate, by providing activation energy to overcome kinetic barrier. ${ }^{3.4}$ But the kinetic enhancement starts to come into conflict with thermodynamics in the carbonation of these minerals. Even though all four reactions above are spontaneous at room temperature (minus value of $\Delta \mathrm{G}_{\text {teaction }}^{\circ}$ in Table 1). calculation on reversal temperature in Table 1 suggests the carbonation should become unfavorable as temperature goes up. The extent of offset paid by enhancing the reaction rate by raising temperature would be especially problematic for MgO being the one most signi-

Table 1. Standard molar free energy of reaction $\left(\Delta \mathrm{G}_{\text {reaction }}^{\circ}\right)$ calculated from tabulated values of standard molar enthalpy of fonmation ( $\Delta$ $\mathrm{H}^{\prime \prime} \mathrm{f}_{\mathrm{f}}$ ) and standard molar entropy ( $\mathrm{S}^{\prime \prime}$. Equilibriun was assunned where the pressures of all the gases are 1 atm (standard state). Calculation was made to get a rough idea on the consequences of raising reaction temperature.

\begin{tabular}{ccc}
\hline Reaction No. $\Delta \mathrm{G}_{\text {reaction }}(\mathrm{KI} / \mathrm{mol})$ at $25^{\circ} \mathrm{C}$ & $\mathrm{T}$ for $\Delta \mathrm{G}_{\text {reactinn }}^{\circ}=0\left({ }^{\circ} \mathrm{C}\right)^{*}$ \\
\hline$(1)$ & -45.2 & 267 \\
$(2)$ & -134.7 & 928 \\
$(3)$ & -12.9 & 598 \\
(4) & -65.7 & 3961 \\
\hline
\end{tabular}

\begin{tabular}{|c|c|c|c|}
\hline Sample & $\begin{array}{l}\text { pre-treatment } \\
\text { at } 300^{\circ} \mathrm{C}^{*} \\
\text { (lst step) }\end{array}$ & $\begin{array}{l}\text { carbonation } \\
\text { at } 300^{\circ} \mathrm{C}^{+} \\
(2 \mathrm{nd} \mathrm{step})\end{array}$ & $\begin{array}{l}\text { Surface area } \\
\mathrm{m}^{2} / \mathrm{g}\end{array}$ \\
\hline $\mathrm{Mg}(\mathrm{OH})_{2}$ & no & no & 28 \\
\hline $\mathrm{M} 300 \mathrm{C}$ & no & $6 \mathrm{l} / 1 \mathrm{~atm} \mathrm{CO}_{2}$ & 59 \\
\hline $\mathrm{MBOOAC}$ & $19 \mathrm{l} / 1 \mathrm{~atm} \mathrm{AI}_{\mathrm{I}}$ & $12 \mathrm{~h} / 1 \mathrm{~atm} \mathrm{CO}_{2}$ & 46 \\
\hline M300V & $19 \mathrm{l} / 10^{-3}$ torr & no & 263 \\
\hline $\mathrm{M} 300 \mathrm{VC}$ & $19 \mathrm{l} / 10^{3}$ tor & $6 \mathrm{~W} / 1 \mathrm{~atm} \mathrm{CO}_{2}$ & - \\
\hline $\mathrm{M} 500 \mathrm{VC}$ & $\begin{array}{l}191 / 10^{-3} \text { tom } \\
\text { at } 500^{\circ} \mathrm{C}\end{array}$ & $\begin{array}{l}6 \mathrm{~W} / 1 \mathrm{~atm} \mathrm{CO}_{2} \\
\text { at } 300^{\circ} \mathrm{C}\end{array}$ & 268 \\
\hline
\end{tabular}

*Calculated from $\Delta G^{\prime \prime}$ eation $=\left(\Delta H^{\prime \prime}\right.$ (earrim $)-T\left(\Delta S^{n}{ }_{\text {eartion }}\right)$.
Table 2. Descriptions of the 2-step reactions carried out for $\mathrm{Mg}(\mathrm{OH})_{2}$. Surface area was measured by BET method.

*The flow rate of the gas was $33 \mathrm{~mL}$ min.

ficantly influenced. Low conversion may be unavoidable in the carbonation of $\mathrm{MgO}$ as reaction tentperature goes up. This conflicting aspect is apparent in previous studies. Study on $\mathrm{Mg}(\mathrm{OH})$ by others verified that delydroxylation and carbonation reactions occurred simultaneously. and conversion to $\mathrm{MgCO}_{3}$ was about $15 \%$ at best. ${ }^{3.4}$ That naxinum conversion was only possible between $300-500^{\circ} \mathrm{C}$. where the rate of dehydroxylation of $\mathrm{Mg}(\mathrm{OH})_{2}$ into $\mathrm{MgO}$ was substantial. At the temperature range. it was observed that decarbonation (reverse reaction) already started to occur. ${ }^{3}$ It was also suggested that the generation of $\mathrm{MgCO}_{3}$ layers on the surface inpeded further carbonation. It was not obvious whether the carbonation was occurring on $\mathrm{MgO}$ or $\mathrm{Mg}(\mathrm{OH})_{2}$, because the reaction mechanism was not clearly elucidated.

In an effort to make separate observations on dehydroxylation and carbonation, which nornally proceed sinultaneously. carbonation on $\mathrm{Mg}(\mathrm{OH})_{2}$ was carried out wia 2-step reactions at $300^{\circ} \mathrm{C}$. Conversion to $\mathrm{MgCO}_{3}$ was known to be low at the temperature. ${ }^{2}$ The rate of delydroxylation of $\mathrm{Mg}(\mathrm{OH})=$ is also very low at $300^{\circ} \mathrm{C}$. But. it can be accelerated by lowering the activation energy by carrying out delydrosylation in dynamic vacuum. It is reported that the apparent activation energies for dehydroxylation of $\mathrm{Mg}(\mathrm{OH})$ increase as following order: in vacuum $(53-126 \mathrm{KJ} / \mathrm{mol})^{9}<$ in helium $(1+6 \mathrm{KJ} / \mathrm{mol})^{-3}$ $<\operatorname{in~} \mathrm{CO}_{2}(304 \mathrm{KJ} / \mathrm{mol})^{3}$. It is also known that the apparent activation energy of the deliydrosylation increases with partial pressure of $\mathrm{H}_{2} \mathrm{O}^{10}$ By cutting off the supply of $\mathrm{CO}_{2}$ and lowering the activation energy. only dehydroxylation reaction could be carried out in the first step (pre-treatment in Table 2). In second step. pure $\mathrm{CO}_{2}$ at 1 atm was flushed over the sample. thereby discouraging dehydroxy lation by raising the activation energy. at the same time encouraging carbonation reaction by supplying reactant. In this consecutive manner. dehydroxylation and carbonation reactions could be carried out separately. Thereby, complication coming from simultaneous reactions could be minimized during observation.

Table 2 provides a list of several different pre-treatments on $\mathrm{Mg}(\mathrm{OH})_{2}$ samples. prior to the carbonation in pure $\mathrm{CO}_{2}$ atmosphere. Carbonation (2nd step reaction) was carried out immediately after the pre-treatment (lst step reaction), by directly exchanging the gas atmosphere without any interruption or cooling. For all but one case. both pre-treatment and carbona- 


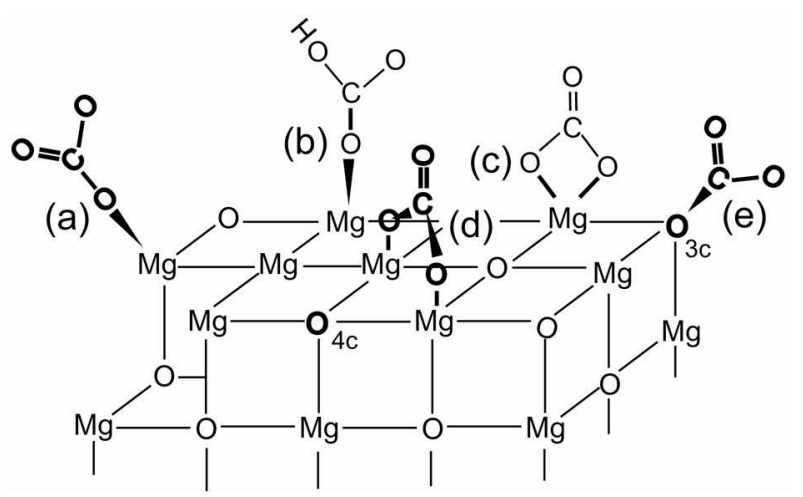

Figure 1. Schematic representations of different confomations of carbonates on the surface of $\mathrm{MgO}$. (a) unidentate carbonate, (b) bicarbonate, (c) bidentate carbonate, (d) bridging carbonate, and (e) multi-coordinated carbonate $\left(\mathrm{O}_{2 \mathrm{k}}-\mathrm{CO}_{2}\right)$.

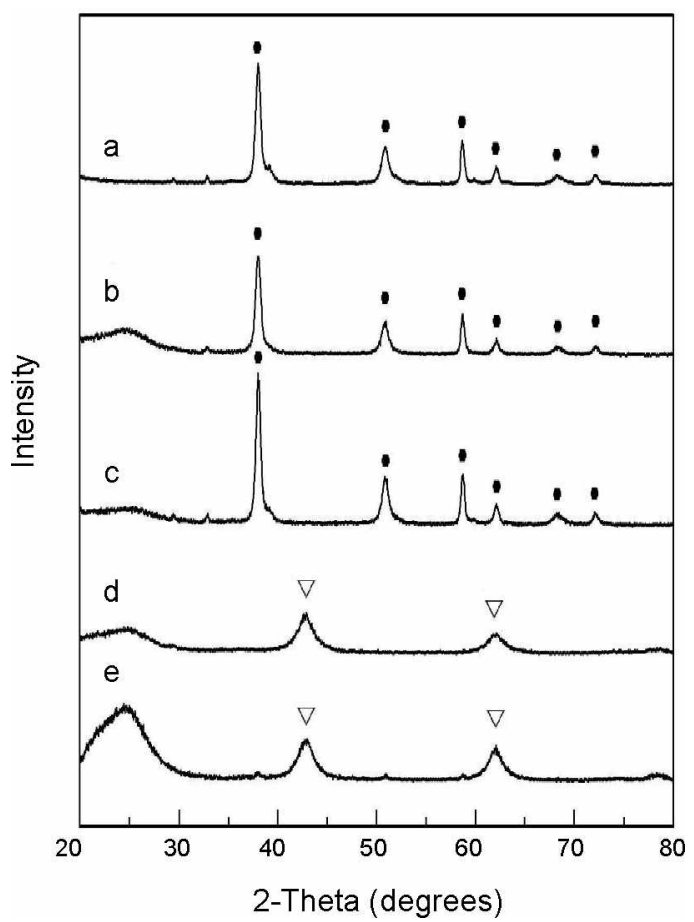

Figure 2. Powder X-ray diffraction pattens obtained after canying out the reactions described in Table 2. (a) $\mathrm{Mg}(\mathrm{OH})$ as prepared by hydration of commercially obtained $\mathrm{MgO}$, (b) exposed to $\mathrm{CO}_{2}$ at 300 ${ }^{\circ} \mathrm{C}$ without any pre-treatment $(\mathrm{M} 300 \mathrm{C})$, (c) exposed to $\mathrm{CO}_{2}$ after pre-treatment in $\mathrm{Ar}$, at $300^{\circ} \mathrm{C}(\mathrm{M} 300 \mathrm{AC})$, (d) after pre-treatment at $300^{\circ} \mathrm{C}$ minder dynamic vacuun (M300V), (e) exposed to $\mathrm{CO}_{2}$ after pre-treatnent under dy nannic vacuum, at $300^{\circ} \mathrm{C}$ (M300VC). Closed cicles $(\bullet)$ and open triangles $(\nabla)$ designate diffraction peaks trom $\mathrm{Mg}(\mathrm{OH})_{2}$ and $\mathrm{MgO}$, respectively

tion reaction were carried out at $300^{\circ} \mathrm{C}$. In order to eliminate 1-coordinated hydroxides on the surface. one specific sample (M500VC) was pre-treated at $500^{\circ} \mathrm{C}$. and cooled down to 300 ${ }^{\circ} \mathrm{C}$ where subsequent carbonation was carried out.

In general. observed features in a solid-gas reaction are strongly related to the characteristics of the solid surface. rather than its bulk. Whereas X-ray diffraction pattern provides features mostly from bulk. FTIR spectnum gives valuable in-

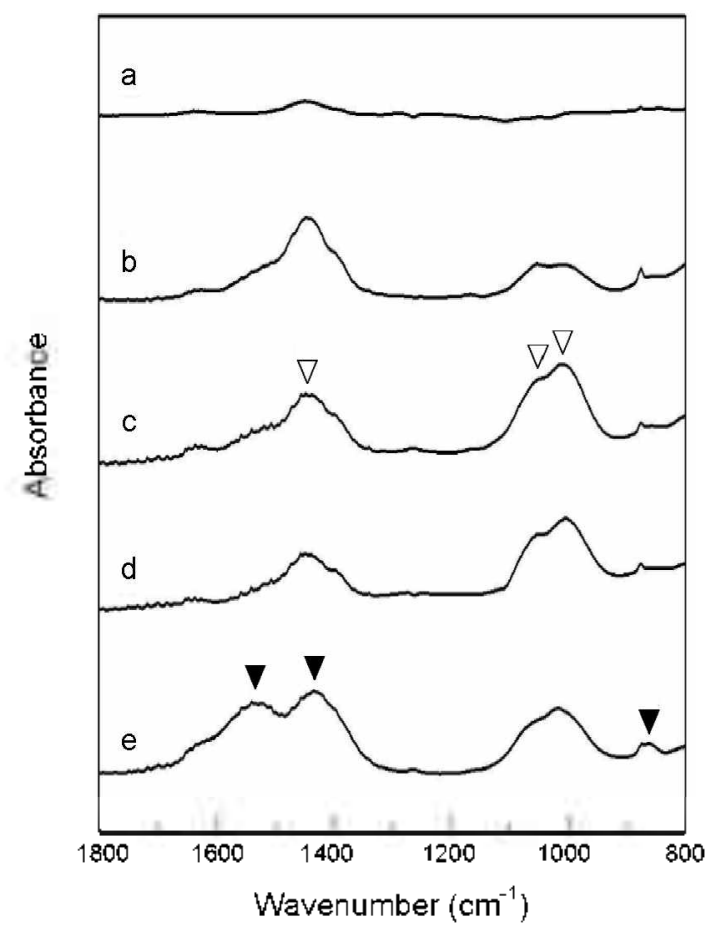

Figure 3. FTIR spectra taken from samples pelletized with $\mathrm{KBr}$, after carying out the reactions described in Table 2. (a) $\mathrm{Mg}(\mathrm{OH})_{2}$ as prepared, (b) M300C, (c) M300AC, (d) M300V, and (e) M300VC. Open triangles $(\nabla)$ and closed triangles $(\mathbf{\nabla})$ designate $\mathrm{MgO}$ and $\mathrm{MgCO}_{3}$, respectively.

formation on the surface of solids. As for the surface carbonates. the assignments of the vibrational frequencies are relatively well documented. ${ }^{1-16}$ Grapluic representations for different carbonates attainable on the surface of $\mathrm{MgO}$ are shown in Figure 1. Four major vibrational frequencies for unidentate carbonates (Figure la) are assigned at $1510-1550,1390-1+10$. $1035 \cdot 1050$, and $860-865 \mathrm{~cm}^{.1}$. $^{11 \cdot 13}$ Vibrational frequencies for bicarbonates (figure $\mathrm{lb}$ ) are assigned at $1655-1658.1405-$ 1419. and $1220-1223 \mathrm{~cm}^{-1}$. $^{11.13-15}$ Bidentate carbonates (Figure lc) show peaks at $1665 \cdot 1670,1325 \cdot 1330.1005-1030$, and $850-855 \mathrm{~cm}^{-1} .^{11-13}$ Key signature of unidentate carbonate distinguishing it from others, is separation between two major peaks which is $100 \mathrm{~cm}^{-1} .{ }^{11}$ Bridging carbonates (Figure ld) and nulti-coordinated carbonates (Figure le) have been seldom observed in any precedent reports on $\mathrm{MgO}$. Only a theoretical calculation was carried out for multi-coordinated carbonate. $\left[\mathrm{O}_{4 \mathrm{c}}-\mathrm{CO}_{2}\right]^{2 *}$. and vibrational frequencies were predicted at $1460,1042,945$, and $794 \mathrm{~cm}^{-1}$. 16

Powder X-ray diffraction patterns and FTIR spectra obtained from the solid samples listed in Table 2 are shown in Figure 2 and Figure 3. respectively. After heating $\mathrm{Mg}(\mathrm{OH})_{2}$ at $300^{\circ} \mathrm{C}$ in pure $\mathrm{CO}_{2}$ atmosphere without any pre-treatment, no apparent change is observed in the powder $\mathrm{X}$-ray diffraction patterns (Figure 2a and 2b). FTIR spectra (Figure $3 a$ and $3 b$ ) show several peaks developed after heating. in very weak intensity. at 1655.1450 .1065 .1010 . and $880 \mathrm{~cm}^{-1}$. They were observed regardless of the $\mathrm{CO}_{2}$ introduction (see Figure $3 \mathrm{~d}$ ), thereby excluding possibility of being surface carbonates. They became more pronunent as heating lasts, and apparently 


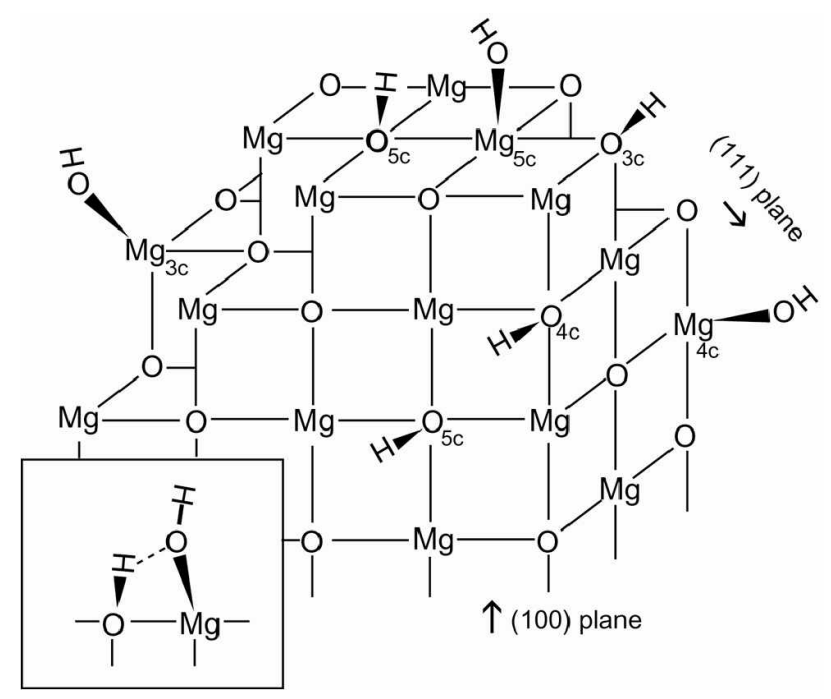

Figure 4. Suhematic representation of detective surtace of Mg( ). 1 Diatgram shows dillerent kinds of surface hydroxides. I lydrogen bonding interaction between l-eoordinated hydroxide (proton aceptor) and muti-cosdinated hydrovide (proston donor) is shess in the inset of the diagram.

were not related to major peaks around $3700 \mathrm{~cm}^{-1}$ in relative intensities. In previous studies on C.P-MgO. these peaks were obscrved from $\mathrm{MgO}$ samples obtained by dehydration of $\mathrm{Mg}(\mathrm{OH})_{2} \mathrm{I}^{-}$Therelore. these peaks were tentatively assigned to $\mathrm{MgO}$ phase on the surface generated by dehydration. It suggests that some $\mathrm{Mg}(\mathrm{OH})_{2}$ on the surface turned into $\mathrm{MgO}$. but intensity from $\mathrm{MgO}$ was very weak. Dehydroxylation reaction was not significant at the temperature. and no carbonation product was observed. Likew isc. no apparent change is observable in the powder X-ray diffraction patterns (Figure 2a and 2c) with the pre-treatment in Ar atmosphere. Very weak sibrational peaks from $\mathrm{MgO}$ can be located in Figure 3c. when the sample was pre-treated in Ar. indicating generation of a small fraction of $\mathrm{MgO}$ phase only on the surface. But. still no carbonate is observed. even after $19 \mathrm{~h}$ contact with pure $\mathrm{CO}_{2}$ at $300^{\circ} \mathrm{C}$. These obsers ations suggest that $\mathrm{Mg}(\mathrm{OH})_{2}$ as prepared docs not $\mathrm{reacl}$ with $\mathrm{CO}_{2}$ (purc/l atm) at $3000^{\circ} \mathrm{C}$. cren with a small fraction of $\mathrm{MgO}$ layer on the surface. This outcome is consistent to the gravimetric analy sis by others on $\mathrm{Mg}(\mathrm{OH})_{2},{ }^{3}$ that exhibitcd the cxtents of both dehydroxylation and carbonation reactions were negligible at $300^{\circ} \mathrm{C}$.

$\mathrm{MgO}$ plase on the surface (dehy droxy lation product). which inherently contains ligh concentration of defective sites. and is more reactive than $\mathrm{MgO}$ as bulk. must be playing an important role in the generation or $\mathrm{MgCO}_{3}$. It has been known that $\mathrm{MgO}$ with high concentration of defects on the surface exhibited unusually high reactivity toward many different chemicals. ${ }^{13,1 \times, 19}$ Such high surface-reactivity was found in MgO samples obtaincd by dehydrating $\mathrm{Mg}(\dot{\mathrm{OH}})_{2}$ in non-cquilibrium condition. such as under fast flow of dry gas. or under dy namic vacuum. Figure $2 \mathrm{~d}$ and figure $3 \mathrm{~d}$ show power $\mathrm{X}$-ray diffraction pattern and FTIR spectrum of $\mathrm{Mg}(\mathrm{OH})_{2}$ heat treatcd at $300^{\circ} \mathrm{C}$ under dy namic vacuum for $19 \mathrm{~h}$. respectively. Whereas dehydroxy lation did not procecd decp into bulk in $\mathrm{Ar}$ or $\mathrm{CO}_{2}$ atmosphere. it turned most of $\mathrm{Mg}(\mathrm{OH})_{2}$ into $\mathrm{MgO}$ under dynamic

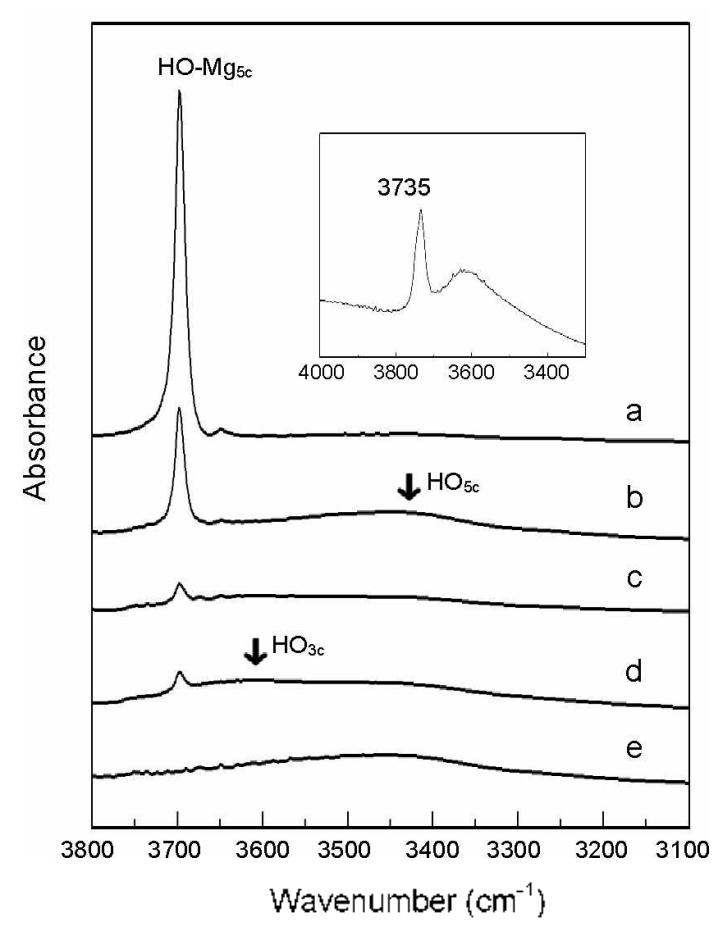

Figure 5. l"III spectra taken Irom the samples exposed to $\mathrm{CO}_{2}$ at $300^{\circ} \mathrm{C}$ for dilterent duration. $\mathrm{CO}_{2}$ gas was introduced immediately after 19 h pre-treatment under drnimic vacuum. (a) not exposed to CO anly pre-treatument was carried out, (b) 6 h exposure, (c) $12 \mathrm{~h}$ exposure, and (d) 18 h expesure. Pre-treatment for (a) to (d) was carried out at $3000^{\circ} \mathrm{C}$. Spectrum (c) was taken alter pre-lreatment at 500 " $\mathrm{C}$, not exposed to $\mathrm{CO}_{2}$. The Fll speetrum in the insel was taken trom $\mathrm{Al}^{3}-\mathrm{Mg}\left(\mathrm{O}\right.$, obtuined by pre-treating $\mathrm{Al}^{2}-\mathrm{Mg}(\mathrm{OH})_{2}$ at $300 \mathrm{O}$ "C. under dinamic vacumn for $19 \mathrm{~h} . \mathrm{Al}^{3}-\mathrm{Mg}(\mathrm{OH})_{2}$ was ssnthesizel by sol-gel/hyper eritieal dṛing.

racuum. as can be seen in Figure 2d. Broadness of the diffraction peaks from $\mathrm{MgO}$ indicates the cry stalline domain is in nano-scale. which is calculated by Scherrer equation to be 9 $\mathrm{nm}$. BET surface arca increased more than 5 -fold $\left(263 \mathrm{~m}^{2} / \mathrm{g}\right)$. compared to $\mathrm{Mg}(\mathrm{OH})$ z heat-1reated under 1 atm. These characteristic changes allude to the generation of highly reactive defective siles on the surface of $\mathrm{MgO}^{13.18 .19}$ When $\mathrm{CO}_{2}$ was introduced after the pre-trealment under dynamic vacuum. generation of surfacc carbonalcs was observed. FTIR spectrum in Figure $3 \mathrm{c}$ shows vibrational peaks at 1533.1430. and $862 \mathrm{~cm}^{-1}$. which can be assigned to unidentate carbonates bonded to $\mathrm{Mg}$ on the surlace. ${ }^{11-1 .}$ Remaining peak around $1050 \mathrm{~cm}^{-1}$ is obscured by overlapping $\mathrm{MgO}$ peaks. No peak was observed which could be assigned to bicarbonates or bidentate carbonates on the surface. Powder X-ray diffraction pattern in Figure 2e shows no peak related to $\mathrm{MgCO}_{3}$. indicating those unidentate carbonates were generated only on the surface. These observations from the 2-step reactions show that delydroxylation process play a critical role in the carbonation of $\mathrm{Mg}(\mathrm{OH})$. via prov iding reactive surfaces of $\mathrm{MgO}$.

There can be many different hydroxyl groups on the surface of $\mathrm{MgO}$. Depending on the coordination environments around $\mathrm{Mg}$. where the hydroxide is bonded to. I-coordinated hydroxides (referred as 'lype A' by others) ${ }^{21-22}$ can be designated as 


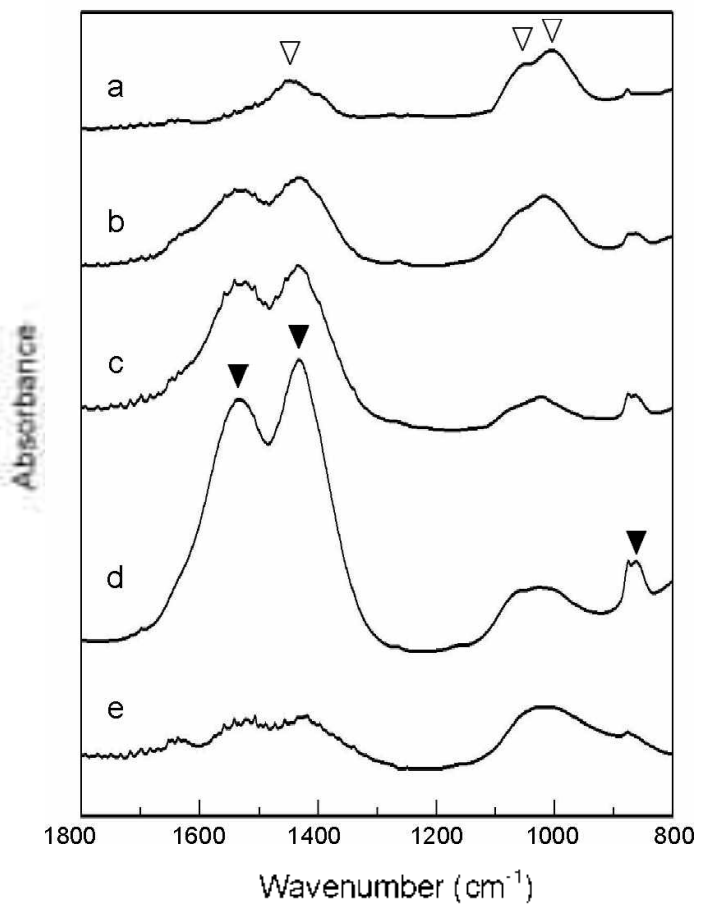

Figure 6. F"TIR spectra taken from the samples exposed $10 \mathrm{CO}_{2}$ at 300 " $\mathrm{C}$ ' lor dillerent duration. $\mathrm{CO}_{2}$ gas was intrexdued immediately. after $19 \mathrm{~h}$ pre-treatment under dynamic vacuum. (a) not exposed to CO., only pre-lreatment wals salried out (b) $6 \mathrm{~h} \mathrm{texposiure:} \mathrm{(c)} 12 \mathrm{~h}$ exposure, and (d) $18 \mathrm{~h}$ exposure. lre-treatment for (a) wo (d) was

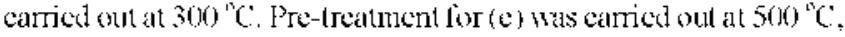
and subseguently exposed to CO for $12 \mathrm{~h}$ al $300^{\circ} \mathrm{C}$. Open triangles $(V)$ and closed triangles ( $\mathbf{V}$ ) designate $\mathrm{MgO}$ and $\mathrm{MgCO}_{3}$, respectively:

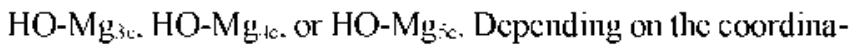
tion environments around lattice $\mathrm{O}$ where $\mathrm{H}$ is bonded to. multicoordinated hydroxides (referred as 'type B' by others) ${ }^{2^{2(1-22}}$ can be designated as $\mathrm{HO}_{3 \mathrm{c}}$. $\mathrm{HO}_{\text {.c. }}$ or $\mathrm{HO}_{\mathrm{c}}$. As illustrated in Figure 4. $\mathrm{Mg}_{\mathrm{i}}$ and $\mathrm{O}_{\mathrm{ic}}$ correspond to the atoms at the corners along high index plane [( 1 1 I) for example of $\mathrm{MgO}$ lattice. Mgtc and $\mathrm{O}_{\mathrm{lc}}$ are sitling along the edges. $\mathrm{Mg}_{\mathrm{sc}}$ and $\mathrm{O}_{5 \mathrm{c}}$ are the ones cmbedded on (100) planes. In hydrogen bonding interaction among these surface hydroxides. multi-coordinated hy droxides behaye as hydrogen donor, whereas l-coordinated hydroxides act as hydrogen acceptor through oxygent. "- This hydrogen bonding interaction is schentatically demonstrated in the inset of the Figure 4 . IJydrogen bonding interaction with the lattice oxygen is also considered to exist. especially for the sample heat treated at high temperature above $5000^{\circ} \mathrm{C}$ Vibrational peaks from multi-coordinated hydroxides get broad. because of these hydrogen bonding interactions. It was reported that peaks shift to lower frequency as number of coordination increases. ${ }^{23.4}$ Therefore. 1-coordinated hydroxides on the surface (proton acceptor) register relatively sharp peaks at high frequency region around $3700 \mathrm{cml}^{-1}$. whereas multi-coordinaled hydroxides (proton donor) on the surface give broad featureless peaks around $3350-3650 \mathrm{~cm}^{-1}$. $2(0)-1+$

Extensive studics have been carried out on the assignments of vibrational frequencics for these surface hydroxyl groups by others. ${ }^{2:-4}$ Bonding in $\mathrm{MgO}$ is known to be highly cova- lent. Not only inductive effect of highly electronegative oxygen. but also clectron donating effect by lone pairs of oxygen has to be counted together in assessing the relative comparison of electron density for $\mathrm{O}-\mathrm{H}$ bonding. Due to these two conflicting factors. some of these reports contain a few contradiciory predictions. especially on the assignments on 'type A' hydroxides. ${ }^{2}$ Results of the ab initio calculation on MgOclusters show the $\mathrm{Mg}-\mathrm{OH}$ bond length of 1-coordinated hydroxides increases as coordination number of Mg increases. ${ }^{\text {i- }}$ The prediction made by the calculation also indicates the vibrational frequency of 1 -coordinated hydroxides shifts to lower frequen$\mathrm{cy}$ as the coordination number of $\mathrm{Mg}$ increases. This prediction suggests the peak for $\mathrm{HO}-\mathrm{Mg}_{\mathrm{s}}$ will be at lower frequency region compared to $\mathrm{HO}-\mathrm{Mg}_{3}$.

After dehýdroxy lation under dỵamic vacuum at $3000^{\circ} \mathrm{C}$. duration of subsequent $\mathrm{CO}_{2}$ contact was cxicnded. and FTIR spectra were taken cicry 6 h. FTIR spectra in Figure 5 and Figure 6 show the spectral regions for surface hydroxides and for surface carbonates. respectively. The fealureless broad peaks spanning from 3300 to $3650 \mathrm{~cm}^{-1}$ in Figure 5 are assigned to multi-coordinated hydroxides (type B). The peak at 3697 $\mathrm{cm}^{-1}$ is assigned to l-coordinated hy droxides (1) pe A) on the surface of $\mathrm{MgO}$. $^{2(1-2 x}$ The peak at $3697 \mathrm{~cm}^{-1}$ was observed at low er frequency in 'ty pe A' region. Therefore, coordination environment around $\mathrm{Mg}$ is tentatively assigned to be $\mathrm{HO}-\mathrm{Mg}_{\mathrm{s}}$. In order to get an additional physical eridenec on this speculation. comparison was made by preparing AP-MgO via sol-gel/ hyper-critical drying. ${ }^{13 .\left\langle L^{i}\right\rangle}$ It is known that $\mathrm{AP}-\mathrm{MgO}$ contains large fraction of high index planes. thereby. high concentration of low coordination sites. such as comers ( $\mathrm{gg}_{3 \mathrm{c}}$ and $\mathrm{O}_{3 \mathrm{c}}$ ) and edges $\left(\mathrm{Mg}_{\mathrm{ks}}\right.$ and $\left.\mathrm{O}_{1 \mathrm{c}}\right)$. Vibrational spectrum taken from this highly defective AP- $\mathrm{MgO}$ was provided in the inset as comparison. The peak for the I-coordinated hydroxides was observed at $3735 \mathrm{~cm}^{-1}$. higher frequenc, than the one observed in the $\mathrm{MgO}$ generated by dehydroxylation of $\mathrm{Mg}(\mathrm{OH})_{2}$. The broad peak for the mulii-coordinated hydroxide is also obseried as shifted to higher frequency region around $3600 \mathrm{~cm}^{-1}$. Considering AP-MgO contains significantly higher proportion of low coordination sites than other $\mathrm{MgO}$. those peaks observed at higher frequencies are tentatively assigned to $\mathrm{HO}-\mathrm{Mg}_{\mathrm{z}}$ and $\mathrm{HO}_{3 \mathrm{c}}$ - Thesc observations corroborate the assignment of $\mathrm{HO}-$ $\mathrm{Mg}_{\mathrm{sc}}$ to the peak at $3697 \mathrm{~cm}^{-1}$. also conforming to the ab initio calculation by others.

In Figure 6. the increase of the peak intensity for the unidentatc carbonates at 1533.1430 . and $862 \mathrm{~cm}^{-1}$ is crident with cxicnded duration of $\mathrm{CO}_{2}$ exposure. No peak assignable to bicarbonates or bidentate carbonates developed. It is interesting to note that the intensity of the hydroxide peak at $3697 \mathrm{~cm}^{-1}$ in figure 5 decreases conconitantly with the increase of those carbonate peaks (comparing Figure 5 and Figure 6). Apparenty. generation of surface carbonates accompanied disappearance of I-coordinated hydroxides on the surface. It is obvious that 1 -coordinated hydroxides on the surface of $\mathrm{MgO}$ are reactant. rather than being by-stander. Careful observation of Figure 5 also exhibited that a featureless broad peak developed around $3450 \mathrm{~cm}^{-1}$ during initial $6 \mathrm{~h}$ period (Figure 5b). which was followed by another development of a broad peak around 3600 $\mathrm{cm}^{-1}$ (Figure 5c and 5d). The broad featureless peaks around 

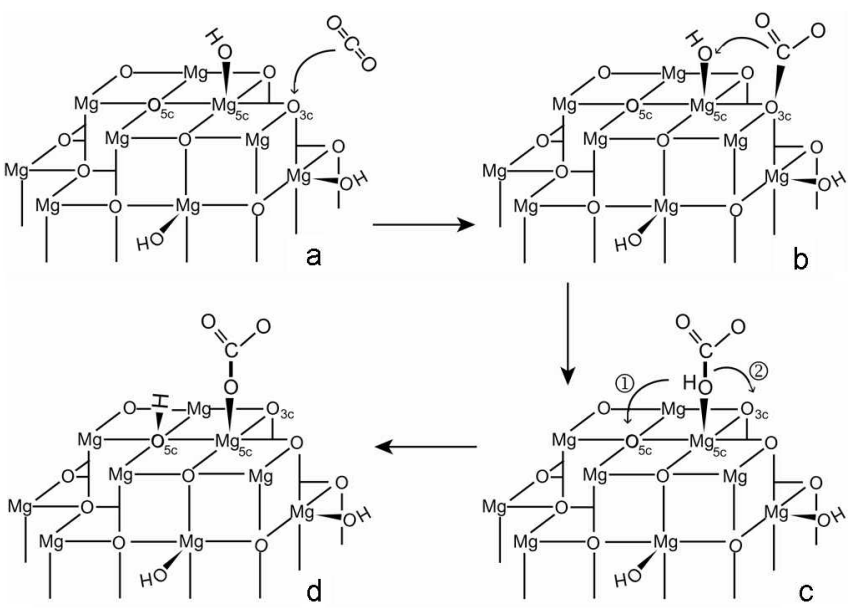

Scheme I Postulated reaction mechanism of the surface carbonation of $\mathrm{Mg}(\mathrm{OH})_{2}$.

3450 and $3600 \mathrm{~cm}^{-1}$ correspond to $\mathrm{HO}_{3}$ and $\mathrm{HO}_{36}$, respectively. Therefore. generation of unidentate carbonate on the surface of $\mathrm{MgO}$ accompanied concurrent demise of 1-coordinated hydroxides. and the development of multi-coordinated hydroxides. as well

In order to see whether the involvement of 1-coordinated hydroxides is necessary for the carbonation, they were intentionally eliminated by pre-treating $\mathrm{Mg}(\mathrm{OH})=$ at $500^{\circ} \mathrm{C}$ (instead of $300^{\circ} \mathrm{C}$ ) under dynamic vacuum (sample M500VC). FTIR spectrum taken after pre-treatment at $500^{\circ} \mathrm{C}$ (Figure 5e) shows no prominent peak around $3700 \mathrm{~cm}^{-1}$, suggesting that the 1coordinated hydroxides were not present on the surface. After the pre-treatment at $500^{\circ} \mathrm{C}$, the sample was exposed to pure $\mathrm{CO}_{2}$ at $300^{\circ} \mathrm{C}$ during $12 \mathrm{~h}$ and not much carbonation occurred as can be seen in Figure 6e.

From these observations. we postulated possible mechanisms of the carbonation reactions at $300^{\circ} \mathrm{C}$. occurring on the reactive $\mathrm{MgO}$ surface generated by dehydroxylation of $\mathrm{Mg}$ $(\mathrm{OH})_{2}$ and schematically proposed them in Scheme I. After dehydroxylation at $300^{\circ} \mathrm{C}$ under dynamic vacuum, $\mathrm{MgO}$ surfaces develop defective sites such as comers and edges. It was reported that the reactivity of defective sites increases as the coordination number decreases. ${ }^{13,18.19}$ Theoretical study by ab initio calculation also showed that $\mathrm{CO}_{2}$ preferably chemisorbs on lower coordinated defective sites. ${ }^{16}$ Therefore. $\mathrm{CO}_{2}$ adsorbs on highly reactive $\mathrm{O}_{3 \mathrm{c}}$ at the apex of the corners (scheme Ia and Ib). Then, $\mathrm{CO}_{2}$ migrates to the adjacent 1-coordinated hydroxide generating a protonated intermediate proposed in Scheme Ic. Subsequent deprotonation generates unidentate carbonate (Scheme Id). At the same time, protonation of lattice oxygen generates multi-coordinated hydroxide on the surface (Scheme Id). In early stage of the carbonation (initial $6 \mathrm{~h}$ ), deprotonation proceeds along path 1 , generating $\mathrm{HO}_{\mathrm{sc}}$. Later. it follows the path 2 generating $\mathrm{HO}_{3 \mathrm{c}}$. The observations made on Figure 5 and Figure 6 conform to this proposed mechanism. As the outcome of these stepwise processes. the FTIR peak for the 1 -coordinated hydroxide would shrink, and at the same time. the peaks for unidentate carbonates and muti-coordinated hydroxides should grow up.
Theoretical calculation on MgO clusters suggested the chemisorption of $\mathrm{CO}_{2}$ on defective sites was non-activated process. and generated multi-coordinated carbonates. without migration. ${ }^{96}$ Because the calculation was carried out on a cluster embedded in a large array of point charges (surrounding). possibility of the $\mathrm{CO}_{2}$ migration was not counted in the theoretical study. Apparently, no such multi-coordinated carbonates were observed in our study. and only unidentate carbonate was generated. Also. it is interesting to note that bicarbonates would be produced if proton migrated to negatively charged end moiety of the carbonate. But. apparently it did not happen and instead. the proton migrated opposite direction toward the surface. to combine with the multi-coordinated lattice oxygen.

\section{Conclusion}

By following 2-step procedure at $300^{\circ} \mathrm{C}$. dehydrosylation and carbonation reactions of $\mathrm{Mg}(\mathrm{OH})_{2}$ were carried out in consecutive manner. thereby trying to see the outcome of each reaction separately. It was shown that carbonation did not occur without preceding dehydroxylation of $\mathrm{Mg}(\mathrm{OH})=$ into $\mathrm{MgO}$. The carbonation product was obtained only on defective $\mathrm{MgO}$ surface. which was in situ generated by delydrosylation of $\mathrm{Mg}(\mathrm{OH})_{2}$ under dynamic vacuum. The carbonation product was unidentate carbonates on the surface. and formation of bicarbonates and bidentate carbonates were not observed.

The generation of unidentate carbonates accompanied concurrent dentise of 1-coordinated lydroxides on the surface of the defective MgO. Without I-coordinated hydroxides on the surface. carbonates were not produced at $300^{\circ} \mathrm{C}$. As carbonation reaction proceeded, population of multi-coordinated hydroxides also increased.

On the basis of the observations made during 2-step reactions. postulated reaction mechanism was proposed for the carbonation of $\mathrm{Mg}(\mathrm{OH})=$ at $300^{\circ} \mathrm{C}$. The reaction mechanism proposed in this report might not be necessarily valid for the reactions occurring at higher temperature than $300^{\circ} \mathrm{C}$. Carbonation reactions of $\mathrm{Mg}(\mathrm{OH})=$ by others were carried out typically around $500^{\circ} \mathrm{C}$. At higher temperature. reaction mechanism almost certainly should get nuch more complex. because all those reactions and changes. such as dehydroxylation, carbonation, decarbonation, translamellar cleavage. and thickening of product layer. would progress simultaneously: Still, the observations made in this study give a very important glimpse into such complex process. Apparently, the carbonation reaction was occurring on the surface of in-situ generated defective $\mathrm{MgO}$. rather than through direct reaction with $\mathrm{Mg}(\mathrm{OH})_{2}$. Therefore, the carbonation of $\mathrm{Mg}(\mathrm{OH})_{2}$ does not appear to proceed via reaction (3) above. Instead, it can be rewritten as followings. $\mathrm{MgO}^{*}$ designates highly reactive $\mathrm{MgO}$ which contains high concentration of defective sites.

$$
\begin{aligned}
& \mathrm{Mg}(\mathrm{OH})_{2}(\mathrm{~s}) \rightarrow \mathrm{MgO}^{*}(\mathrm{~s})+\mathrm{H}_{2} \mathrm{O}(\mathrm{g}) \\
& \mathrm{MgO}^{*}(\mathrm{~s})+\mathrm{CO}_{2}(\mathrm{~g}) \rightarrow \mathrm{MgCO}_{3}(\mathrm{~s})
\end{aligned}
$$

With $\mathrm{MgO}^{*}$ involved, thermodynanuic parameters for the 
above reactions cannot be known accurately without carefully designed experiments. But. it is interesting to note that reaction (6) actually occur at $300^{\circ} \mathrm{C}$. in dy namic condition. Calorimetric study on $\mathrm{MgO}$ with high surface area showed that the standard heat of formation for $\mathrm{MgO}^{*}$ is substantially higher than bulk $\mathrm{MgO}^{39}$ The study was carried out only up to 100 $\mathrm{m}^{2} / \mathrm{g} \mathrm{BET}$ surface area. An intriguing curiosity arises on the outcome if the size of the $\mathrm{MgO}^{*}$ particles gets very small while raising surface area further in large extent. We are on further pursuing for the answer to this intriguing question.

\section{References}

1. Hahnann, M.; Steinberg, M. Greenhouse Gas Carbon Dioxide Mitigation, Science and Technologv. Lewis Publications: London, U. K., 1999.

2. Lackner, K. S.: Wendt, C. H.: Butt, D. P.; Jovce, E. L., Tr; Sharp, D. H. Energv $1995,20(11), 1153$

3. Butt, D. P.: Lackier, K. S.: Wendt, C. H.; Conzone, S. D.: Kung, H.: Lu, Y.; Bremser, T. K. J Amer Ceram Soc. 1996, 79(7), 1892.

4. Béarat, H.; McKelwy; M. J.; Chizmeshya, A. V. G.; Sharma, R.; Carpenter, R. W. J. Aner: Ceram. Soc, 2002, $85(4), 742$

5. Moodie, A. F. Warble, C. E. J. Cryst. Growth 1986, 74, 89.

6. Naono, H. Colloids Surf. 1989, 37, 55 .

7. McKelvy, M. I.; Shanna, R.; Chizmeshya, A. V. G.: Carpenter, R. W. Streib, K. Chent. Hater: 2001, I3, 921 .

8. Gillan, M. T. Kantorovich, L. N.; Lindan, P. J. D. Current Opinion in Solid State \& M haterials Science 1996, 1, 820.

9. Gregg, S. J.: Razouk, R. I. J. Chem. Soc. 1949, S36.
10. Garn. P. D.: Freund, F. Trans. J. Bit. Ceram. Soc. 1975, 7*(1), 23.

11. Evans, J. V; Whateley, T. L. Trans. Faraday Soc. 1967, 63, 2769.

12. Fukunda, Y.: Tanabe, K. Bull Chem. Soc. Jpm 1973, \$6, 1616.

13. Stark, J. V.; Park, D. G.; Lagadic, I.; Klabunde, K. T. Chem. Mater: 1996, $8,1904$.

14. Philipp, R.: Omata, K.; Aoki, A.: Fujimoto, K. J. Catal. 1992. 134,422

15. Philipp, R.; Fujimoto, K. J. Phvs. Chent. 1992, 96, 9035.

16. Pacchioni, G. Surf. Sci. 1993, 281, 207.

17. Lee, M. H.: Park, D. G. Bull Korean Chem. Soc. 2003, 2+(10), 1437.

18. Itoh, H.; Utamapanya, S.; Stark, J. V.; Klabunde, K. J; Schlup, J. R. Chem. Naten 1993, 5,71

19. Koper, O. B.: Lagadic, I.: Volodin, A.: Klabunde, K. I. Chem. Mater: 1997, 9.2468.

20. Anderson, P. J.: Horlock, R. F, Oliver, I. F. Trans. Farada Soc. $1965,61,2754$.

21. Coluccia, S.; Marchese, L.; Lavagnino, S.; Anpo, M. Spectrochim .4cta $11987 .+3(12), 1573$.

22. Knözinger, E.; Jacob, K.; Singh, S.; Hofmann, P. Suff Sci. 1993. 290,388 .

23. Tsy ganento, A. A.; Filimonov, V. N. J. Hot. Smzc. 1973, 19. 579.

24. Smimov, E. P.; Tsyganenko, A. A. Reac. Kinet. Catal Lett. 1984, $26(3-4), 405$.

25. Takezawa, N. Bull. Chem. Soc. Jpn 1971, 4t, 3177.

26 Jones, C. F; Reeve, R. A; Rigg, R.; Segall, R. L.; Smart, R. C.; Turner, P. R. J. Chem. Soc., Faraday Trans. 1 1984, 80, 2609.

27. Lavalley, I. C.: Bensitel, M.; Gallas, I. P.; Lamotter, I.: Busca, G.; Lorenzelli, V. J. Mol. Stric. 1988, 175, 453.

28. Shido, T.; Asahura, K.; Iwasawa, Y. J. Chem. Soc., Forndav Trants. $11989,85(2), 441$

29. Beruto, D.: Rossi, P. F.: Searcy, A. W. J. Ph, Chem 1985, 89, 1695. 